\title{
Imigração, absorção social e matrimônio: trajetórias de açorianos e reinóis na Vila de Paranaguá (Capitania de São Paulo, década de 1780)
}

\section{Immigration, social absorption and marriage: trajectories of Azoreans and Reigns in the municipality of Paranaguá (Captaincy of São Paulo, 1780s)}

\author{
André Luiz Moscaleski Cavazzani* \\ Sandro Aramis Richter Gomes*
}

\begin{abstract}
Resumo
Este artigo comporta uma investigação acerca dos processos de inserção de seis imigrantes açorianos e reinóis na vila de Paranaguá ao longo dos anos 1780.0 objetivo fundamental deste estudo é evidenciar as condições socioeconômicas desse contingente de imigrantes no contexto em que contraíram matrimônio. Desse modo, trata-se de salientar a natureza das ocupações econômicas desses imigrantes e o perfil dos indivíduos que compunham o seu círculo de relações sociais. Inicialmente, demonstra-se que, naquele decênio, os imigrantes estavam distribuídos em três categorias profissionais (comerciantes de secos e molhados, marítimos e artífices). Assim, argumenta-se que esses açorianos e reinóis, ao tempo de seu matrimônio, estavam acomodados em posições subalternas na vida comercial da vila de Paranaguá. Em sua maior parte, esses imigrantes se estabeleceram em Paranaguá na menoridade e foram treinados precocemente nas lides comerciais. Nesse contexto, a inserção no mercado matrimonial e a abertura de um pequeno comércio varejista eram os limites das oportunidades desses portugueses. Segundo, é evidenciado que naquela vila os imigrantes não afortunados formavam uma comunidade paralela à dos imigrantes abastados. Assim, os imigrantes de origem portuguesa cujas trajetórias são estudas neste artigo pertenciam a um circuito de relações sociais composto por imigrantes detentores de uma condição social modesta. Portanto, este artigo desenvolve um entendimento sobre as características e os limites das oportunidades sociais angariadas por imigrantes que se estabeleceram em uma área do litoral sul da Capitania de São Paulo.
\end{abstract}

Palavras-chave: hierarquia social; matrimonio; sociedade litorânea; imigração.

*Doutor em História Social pela USP. Coordenador do Curso de História do UNINTER. E-mail: andrexcava@ hotmail.com

${ }^{* *}$ Doutor em História pela UFPR. E-mail: argomes8@gmail.com 


\begin{abstract}
This article presents a survey on the processes of insertion of six Azoreans and Portuguese mainland immigrants in the municipality of Paranaguá during the 1780s. The main objective of this study is to show the socioeconomic conditions of the contingent of immigrants in the context of their marriage. In this way, it is a matter of emphasizing the nature of the economic occupations of the Azoreans and Portuguese and the profile of the individuals who made up their circle of social relations. It is shown that the immigrants were distributed in two professional categories (sea faring craftsmen, and small merchants). Thus, it is argued that these Azoreans and Portuguese, at the time of their marriage, were accommodated in subaltern position in the commercial life of municipality of Paranaguá. For the most part, these immigrants settled in Paranaguá as children and were trained early in the commercial activities. In this context, an insertion in the marital market and an opening of a small retail trade were the limits of opportunities of the Azoreans and Portuguese. It is evidenced that immigrants are not fortunate to form a community in that municipality. Thus, immigrants of Portuguese origin who married in the 1780s in Paranaguá were of modest social condition. Therefore, this article highlights the limits of social opportunities of immigrants who settled in the Captaincy of São Paulo in the second half of eighteenth century.
\end{abstract}

Keywords: coastal society; immigration; marriage; social hierarchy.

\title{
Introdução
}

Este artigo comporta uma investigação a respeito das condições sociais e econômicas de seis imigrantes provenientes do Arquipélago dos Açores e do Reino de Portugal que contraíram matrimônio na vila paulista de Paranaguá, no contexto da década de 1780. O argumento central deste estudo é de que esses imigrantes, na época de suas núpcias, estavam situados em posições subalternas na vida mercantil. Dessa forma, neste estudo são evidenciadas as limitações das oportunidades sociais e econômicas de jovens imigrantes em uma vila do Brasil colonial. Mais precisamente, são estudados os aspectos da posição e das oportunidades sociais de indivíduos que participaram do fluxo de migração de indivíduos de origem portuguesa para o extremo sul da Capitania de São Paulo ocorrido na segunda metade do século XVIII.

Nesse quadro, são apresentados indícios de que os imigrantes arrolados neste estudo mantinham relações horizontalizadas com brasileiros e 
portugueses distinguidos pela modesta condição social. Esse caráter modesto era decorrente, por exemplo, da posição inferior na hierarquia de comerciantes. Argumenta-se, assim, que essa posição inferior era evidenciada pela dificuldade de alguns dos imigrantes se sedentarizarem como proprietários de armazéns e também pelo fato de limitarem suas atividades ao âmbito do pequeno comércio varejista.

Portanto, na vila de Paranaguá os imigrantes não afortunados formavam uma comunidade. No interior dessa comunidade estavam congregados indivíduos que desempenhavam análogas atividades profissionais e vivenciaram, ao mesmo tempo, semelhantes experiências sociais, tais como absorção a parentelas enraizadas naquele município. Dessa maneira, a presente investigação tem a finalidade de produzir um conhecimento atinente às formas e aos limites do enraizamento e mobilidade social de membros da comunidade étnica portuguesa em uma vila litorânea no contexto das décadas finais do século XVIII. ${ }^{1}$

O presente artigo é desenvolvido em quatro etapas. Na primeira etapa é empreendida uma análise do estado da arte sobre a história da imigração de europeus no Brasil Meridional, com especial ênfase para os estudos referentes à presença europeia no território do atual Estado do Paraná. Assim, trata-se de salientar a carência de estudos atinentes às formas de inserção de imigrantes na hierarquia de sociedades sulinas.

Nesse particular, compete destacar que permanece pouco desenvolvida a compreensão respeitante às desigualdades econômicas existentes entre os membros de comunidades étnicas que se formaram no território do atual Estado do Paraná, ao longo dos séculos XVIII e XIX. O estudo sobre o comportamento demográfico dessas comunidades persistiu como o elemento central

\footnotetext{
${ }^{1}$ Comumente, os estudos atinentes à presença de imigrantes europeus no atual Paraná, no contexto dos séculos XIX e XX, destacaram a relevância dos estudos do sociólogo alemão Ferdinand Tönnies para a compreensão dos fatores de unidade de uma comunidade étnica. Em síntese, tais estudos são orientados pelo propósito de salientar, a partir da matriz de análise inerente aos trabalhos do citado sociólogo, os fatores de unidade de um grupo étnico. A esse respeito, ver BIDEAU, Alain e NADALIN, Sérgio Odilon. Une communauté allemande au Brésil: de l'immigration aux contacts culturels, XIX ${ }^{e}$-XX ${ }^{e}$ siècle. Paris: Ined, 2011; HELFENSTEIN, Janaína Cristiane da Silva. Entre a vida comunitária e a vida conjugal: a composição das famílias luteranas de Imbituva, Paraná (1943-1959). Dissertação (Mestrado em História). Curitiba: Universidade Federal do Paraná, 2014; SCARPIM, Fábio Augusto. Bens simbólicos em laços de pertencimento: família, religiosidade e identidade étnica nas práticas de transmissão de nomes de batismo em um grupo de imigrantes italianos (Campo Largo-PR, 1878-1937). Dissertação (Mestrado em História). Curitiba: Universidade Federal do Paraná, 2010. De outra parte, argumenta-se neste artigo que a historiografia permanece carente de estudos que evidenciem os fatores dos distanciamentos entre aos imigrantes. Busca-se, assim, salientar a natureza socialmente segmentada de um grupo que possuía traços culturais e origens históricas comuns e instalaram-se em uma sociedade litorânea brasileira da segunda metade odo século XVIII.
} 
nos estudos sobre a imigração em áreas do Brasil Meridional. No decorrer desse estágio da análise, portanto, é sustentado o argumento de que o avanço no conhecimento sobre a imigração no Sul do Brasil demanda a formulação de uma análise atenta à natureza do poder econômico e das oportunidades sociais dos imigrantes.

No segundo estágio da análise é evidenciado que a principal ocupação exercida pelos portugueses estabelecidos em Paranaguá era o comércio. Mais precisamente, uma das mais frequentes oportunidades econômicas obtidas por jovens imigrantes, naquela vila, era mover-se da condição de caixeiro para a condição de comerciante varejista. Nesse âmbito, trata-se de salientar que, em Paranaguá, nos anos 1780, estava consolidada uma forma de enraizamento de açorianos e reinóis que perdurou, até o século XIX, em praças mercantis maiores, tais como o Rio de Janeiro. Esse enraizamento consistia na obtenção do emprego de caixeiro e, por conseguinte, na inauguração de um armazém de secos e molhados. ${ }^{2}$

Em resumo, nessa etapa da análise é demonstrado o argumento segundo o qual, no município de Paranaguá, nos anos 1780, os limites da oportunidade econômica dos jovens imigrantes eram a extinção de seus vínculos de dependência para com os seus antigos patrões e a inserção no mercado matrimonial. Ao mesmo tempo, nessa seção do artigo é principiada a demonstração do argumento de que os imigrantes, em Paranaguá, formavam uma comunidade. Os membros dessa comunidade possuíam análoga situação econômica. Tal situação era marcada pela modesta inserção na vida comercial.

Na terceira etapa da análise é salientado que os jovens noivos de origem portuguesa, na vila de Paranaguá dos anos 1780, diferenciavam-se em virtude do modo de atuação na vida mercantil. Os açorianos e reinóis arrolados neste estágio possuíam uma condição econômica mais modesta em relação aos jovens imigrantes estudados no primeiro estágio do artigo. Dessa forma, os estudos de casos realizados nesta etapa da análise permitem ressaltar aspectos das desigualdades internas à comunidade étnica portuguesa formada em Paranaguá no fim do século XVIII.

$\mathrm{Na}$ quarta etapa do estudo é destacado que havia ocasiões nas quais os imigrantes, quando se estabeleciam em Paranaguá, já possuíam uma qualificação profissional. Mais precisamente, eles atuavam em ofícios artesanais desde a época em que residiam nos Açores, em Portugal ou em uma vila colonial

\footnotetext{
${ }^{2}$ Referente aos aspectos da vida mercantil no Rio de Janeiro dos primórdios do século XIX, ver GORENSTEIN, Riva e MARTINHO, Lenira. Negociantes e Caixeiros na Sociedade da Independência. Rio de Janeiro: Secretaria da Cultura, 1993.
} 
brasileira. Dessa maneira, a forma de ingresso do imigrante na sociedade de Paranaguá, nos anos 1780, não era caracterizada por etapas previsíveis. Ou seja, esse ingresso não era marcado, em todos os casos, pela obtenção de um aprendizado nas atividades comerciais, notadamente a partir do exercício da função de caixeiro ou de guarda-livros.

A semelhança entre os membros das três categorias de imigrantes era a sua modesta condição nos ramos de atividade profissional a que se dedicaram. Ao mesmo tempo, são apresentados indícios de que os indivíduos com os quais eles mantinham relações sociais mais sólidas eram seus compatriotas. Esses compatriotas, por sua vez, também eram distinguidos pela posição subalterna na hierarquia social de Paranaguá.

$* * *$

A execução deste artigo é realizada a partir da análise de dispensas matrimoniais. Esses documentos eram produzidos pela Igreja Católica. As dispensas matrimoniais aqui utilizadas estão sob a guarda do Arquivo Metropolitano Dom Leopoldo e Silva, da Mitra Diocesana de São Paulo, a qual está situada na capital paulista. ${ }^{3}$

Dentre as finalidades das dispensas matrimoniais estava atestar que o imigrante estava habilitado a contrair matrimônio no Brasil. Para a emissão desse atestado, sacerdotes atuantes nas vilas coloniais arrolavam testemunhas e as indagavam sobre as origens familiares e atividades profissionais dos imigrantes que pretendiam contrair matrimônio. Um objetivo central da consulta a essas testemunhas era a comprovação de que o imigrante era solteiro e não prometera casamento a alguma mulher. A partir da coleta dessas informações, os sacerdotes autorizavam a realização das núpcias entre o imigrante e uma integrante da sociedade receptora. ${ }^{4}$

Contudo, as dispensas existentes para a vila de Paranaguá nos anos 1780 diferenciam-se em virtude da maior ou menor quantidade de informações sobre os imigrantes. Há, pois, dispensas lacônicas, as quais não contêm informações sobre ocupação econômica e o processo de inserção do imigrante no Brasil. Desse modo, o critério empregado neste artigo para a seleção de dispensas matrimoniais consistiu em arrolar apenas aquelas que informavam sobre a natureza das atividades profissionais e o processo de inserção

\footnotetext{
${ }^{3}$ Esse arquivo está situado na Avenida Nazaré, n. 993, bairro do Ipiranga, cidade de São Paulo.

${ }^{4}$ Para o conhecimento da finalidade e das características do conteúdo das dispensas matrimoniais, ver GOLDSCHMIDT, Eliana Rea. Casamentos mistos: liberdade e escravidão na São Paulo colonial. São Paulo: Annablume/Fapesp, 2004; LOPES, Eliana Cristina. O revelar do pecado: os filhos ilegítimos na São Paulo do século XVIII. São Paulo: Annablume/Fapesp, 1998.
} 
do noivo nas lides comerciais desde o período em que aportava na cidade do Rio de Janeiro.

A lacuna fundamental dos processos de dispensas matrimoniais realizados em Paranaguá, nos anos 1780, diz respeito às informações sobre as mulheres com as quais os jovens imigrantes contraíam matrimônio. Portanto, as dispensas não trazem informações detalhadas sobre a condição social da família da nubente. ${ }^{5}$

Por outro lado, essas fontes permitem o conhecimento do perfil social de membros do círculo de relações sociais dos noivos açorianos e reinóis. Esse conhecimento é viabilizado pelo fato de que as testemunhas arroladas mencionavam as atividades econômicas que exerciam e os aspectos de seu processo de inserção na sociedade de Paranaguá.

\section{A imigração no Brasil Meridional e as linhas de força da historiografia: a ênfase no comportamento demográfico e o problema das desigualdades entre compatriotas}

A historiografia acerca da imigração no Brasil Meridional e, em particular, na Província do Paraná, é marcada por estudos atinentes aos padrões demográficos de comunidades étnicas constituídas a partir da segunda metade do século XIX. Dessa maneira, tais estudos comportam análises dos fatores sociais e econômicos que engendraram mudanças sobre as taxas de natalidade, nupcialidade e mortalidade de distintas comunidades de origem europeia. Em resumo, tais estudos são orientados pelo propósito de assinalar a relação entre o comportamento demográfico e o ritmo de integração dos imigrantes na sociedade receptora. ${ }^{6}$

\footnotetext{
${ }^{5}$ Para uma análise sobre a operacionalidade do emprego de fontes paroquiais para o estudo da sociedade colonial brasileira, ver FRAGOSO, João; GUEDES, Roberto; Sampaio, Antônio Carlos Jucá (Org.). Arquivos paroquiais e história social na América Lusa: métodos e técnicas de pesquisa na reinvenção de um corpus documental. Rio de Janeiro: Mauad, 2014.

${ }^{6}$ Para o conhecimento dos argumentos e resultados cruciais dessa vertente de estudos sobre imigração, ver BALHANA, Altiva Pilatti. Santa Felicidade. Uma paróquia Veneta no Brasil. Curitiba: Fundação Cultural, 1978; HOBARTIUK, Paulo. Imigração ucraniana no Paraná. União da Vitória: Fundação Faculdade de Filosofia, Ciências e Letras de União da Vitória, 1989; NADALIN, Sergio Odilon. A Origem dos noivos nos registros de casamentos da Comunidade Evangélica Luterana de Curitiba. Dissertação (Mestrado em História). Curitiba: Universidade Federal do Paraná, 1974; MACHADO, Cacilda da Silva. De uma familia imigrante: sociabilidades e laços de parentesco. Curitiba: Aos Quatro Ventos, 1998; NADALIN, Sérgio Odilon. Une paroisse germanique au Brésil: la communauté évangélique luthérienne à Curitiba entre 1866 et 1969. Tese (Doutorado em História e Geografia das Populações). Paris: École des Hautes Études em Sciences Sociales, 1978; QUEIROZ, Maria Luiza Bertulini. Paróquia de São Pedro do Rio Grande: estudo de história demográfica (1737-1850). Tese (Doutorado em História). Curitiba: Universidade Federal do Paraná, 1992; RANZI, Serlei Fischer. Alemães católicos: um estudo comparativo de famílias em Curitiba (1850-1919). Tese (Doutorado em História). Curitiba: Universidade Federal do Paraná, 1996; WACHOWICZ, Ruy Cristovam. Abranches: paróquia da imigração
} 
De outra parte, cabe salientar que há a vertente de estudo dedicada à compreensão dos aspectos culturais e das formas de interações sociais inerentes às comunidades étnicas em áreas do Sul do Brasil. Essa vertente forneceu, pois, uma contribuição para o entendimento sobre as formas de organização interna dessas comunidades. ${ }^{7}$ Porém, permanece pouco desenvolvido o entendimento respeitante aos processos de diferenciação socioeconômica entre imigrantes integrados em áreas sulinas. ${ }^{8}$

As mais consistentes contribuições ao estudo da inserção de parentelas de origem portuguesa na hierarquia de sociedades receptoras foram desenvolvidas a partir dos anos 2000, com especial ênfase para o caso do Rio Grande do Sul do século XVIII. ${ }^{9}$ Presentemente, a historiografia tem conferido atenção, de forma mais sistemática, sobre a natureza e limites das oportunidades sociais de imigrantes das ilhas atlânticas e do Reino de Portugal em áreas do Brasil Meridional no contexto do período colonial. ${ }^{10}$

polonesa. Dissertação (Mestrado em História). Curitiba: Universidade Federal do Paraná, 1974.

${ }^{7}$ ANDREAZZA, Maria Luiza. O paraíso das delícias: um estudo da imigração ucraniana (1895-1995). Curitiba: Aos Quatro Ventos, 1999; LOLLA, Beatriz Pellizzetti. L'idéologie et la créativité de l'immigration européenne au Brésil. Rio do Sul: s/e, 2005; SEYFERTH, Giralda. Nacionalismo e Identidade Étnica: a ideologia germanista e o grupo étnico teuto-brasileiro numa comunidade do Vale do Itajaí. Florianópolis: Fundação Catarinense de Cultura, 1982.

${ }^{8}$ Concernente ao caso do Paraná, o estudo que propicia um conhecimento de aspectos da inserção de imigrantes alemães na hierarquia social da cidade de Curitiba no século XIX foi produzido por Denise Colatusso. Ver COLATUSSO, Denise Eurich. Imigrantes alemães na hierarquia de status da sociedade luso-brasileira (Curitiba, 1869 a 1889). Dissertação (Mestrado em História). Curitiba: Universidade Federal do Paraná, 2004.

${ }^{9}$ HAMEISTER, Martha Daisson. Para dar calor à nova povoação: estratégias sociais e familiares a partir dos registros batismais da Vila do Rio Grande (c.1748-c.1763). Tese (Doutorado em História Social). Rio de Janeiro: Universidade Federal do Rio de Janeiro, 2006; MARQUES, Rachel dos Santos. Por cima da carne seca: hierarquia e estratégias sociais no Rio Grande do Sul (c.1750-1820). Curitiba: Universidade Federal do Paraná, 2012. Ao mesmo tempo, o estudo sobre o enraizamento de imigrantes provenientes do Arquipélago dos Açores permanece mais desenvolvido para o caso do Rio Grande do Sul. Ver BARROSO, Vera. Açorianos no Brasil: história, memória, genealogia e historiografia. Porto Alegre: EST, 2002; FORTES, João Borges. Presença lusa na formação sul-rio-grandense. Porto Alegre: Martins Livreiro, 1978 (1932). Uma tarefa incompleta na historiografia consiste, portanto, na comparação sobre as oportunidades e destinos sociais entre imigrantes açorianos e reinóis. Trata-se, pois, de uma tarefa executada neste artigo por meio da atenção ao caso da vila de Paranaguá setecentista. Um estudo atinente à presença de açorianos no Sudeste brasileiro, em fins do século XVIII, foi realizado por LIMA, Carlos Alberto Medeiros. Sobre migrações para a América Portuguesa: o caso do Rio de Janeiro, com especial referência aos açorianos (1786-1844). In: Estudos Ibero-Americanos, v. 26, n. 2, 2000, pp. 91-120.

${ }^{10}$ CAVAZZANI, André Luiz Moscaleski. Tendo o sol por testemunha: população portuguesa na Baía de Paranaguá (c. 1750-1830). Tese (Doutorado em História Social). São Paulo: Universidade de São Paulo, 2013; CAVAZZANI, André Luiz Moscaleski e GOMES, Sandro Aramis Richter. Antônio Vieira dos Santos: reminiscências e outros escritos. Curitiba: Editora da Universidade Federal do Paraná, 2014; SCOTT, Ana Volpi (Org.). Gente das Ilhas: trajetórias transatlânticas dos Açores ao Rio Grande de São Pedro entre as décadas de 1740 e 1790 . São Leopoldo: Oikos, 2014. 
Em síntese, o desenvolvimento dessa perspectiva de estudo propicia uma compreensão sobre os aspectos das desigualdades sociais e das relações de dependência e dominação econômica que existiram entre os imigrantes de origem portuguesa no Sul do Brasil. De todo o modo, mantém-se pouco frequente o emprego do método de análise comparada de trajetórias para o conhecimento sobre as formas de enraizamento de imigrantes e organização de comunidades étnicas na mencionada região.

Os estudos de trajetórias permanecem periféricos no rol de estudos atinentes ao tema da imigração no Sul e, em particular, no território do atual Estado do Paraná. ${ }^{11}$ Nesse âmbito, o estudo sobre as atividades econômicas e formas de sociabilidade de indivíduos não pertencentes às elites sociais desse território e, em especial, da sua área litorânea não obtiveram significativo desenvolvimento. ${ }^{12} \mathrm{Na}$ historiografia brasileira há, pois, maior inclinação para o estudo sobre as atividades econômicas e a formação de fortunas dos negociantes abastados ao longo dos períodos colonial e imperial. ${ }^{13}$

Dessa forma, a consecução das etapas seguintes do artigo possibilita o entendimento sobre as principais formas de absorção de imigrantes de origem portuguesa na hierarquia de uma vila litorânea na segunda metade do século XVIII. Nesse quadro, o argumento central sustentado nessas etapas subsequentes afirma que a estratificação dos imigrantes em posições subalternas da vida mercantil era a principal oportunidade socioeconômica por eles obtida. Tal estratificação era operacional para eles se libertarem da dominação sobre

\footnotetext{
${ }^{11}$ Dentre os estudos sobre imigrantes no Paraná que consistem em análises de trajetórias, ver CARVALHO NETO, João Baptista Penna de. Floriano Essenfelder: a trajetória de um empresário. Dissertação (Mestrado em História). Curitiba: Universidade Federal do Paraná, 1992; NADALIN, Sérgio Odilon e MACHADO, Cacilda da Silva (Org.). Memórias de Gustav Hermann Strobel: relatos de um pioneiro da imigração alemã no Brasil. Curitiba: Instituto Memória, 2014.

${ }^{12} \mathrm{O}$ mais completo estudo sobre indivíduos não afortunados em Paranaguá diz respeito ao período da segunda metade do século XIX. Ver LEANDRO, José Augusto. Gentes do grande mar redondo: riqueza e pobreza na Comarca de Paranaguá (1850-1888). Tese (Doutorado em História). Florianópolis: Universidade Federal de Santa Catarina, 2003. Concernente ao caso do município de Paranaguá no século XVIII, a análise sobre a sociedade local não avançou para além do estudo de variações do comportamento demográfico entre as décadas de 1770 e 1800 . Ver MEQUELUSSE, Jair. A população da vila de Paranaguá no final do século XVIII, segundo as listas nominativas de habitantes. Dissertação (Mestrado em História). Curitiba: Universidade Federal do Paraná, 1975.

${ }^{13}$ DOURADO, Bruna Iglezias Motta. Comércio de grosso trato e interesses mercantis no Recife, Pernambuco (c. 1837- c. 1871). Tese (Doutorado em História). Niterói: Universidade Federal Fluminense, 2015; FLORENTINO, Manolo e FRAGOSO, João. $O$ Arcaísmo como Projeto: Mercado atlântico, sociedade agrária e elite mercantil em uma economia colonial tardia. Rio de Janeiro, c. 1790 - c. 1840. Rio de Janeiro: Civilização Brasileira, 2001; FRAGOSO, João. Homens de grossa aventura: acumulação e hierarquia na praça mercantil do Rio de Janeiro (1790-1830). Rio de Janeiro: Civilização Brasileira, 1998; OSÓRIO, Helen. Comerciantes do Rio Grande de São Pedro: formação, recrutamento e negócios de um grupo mercantil da América Portuguesa. In: Revista Brasileira de História, vol. 20, n. 39, p. 99-134, 2000.
} 
eles exercida por seus antigos patrões e também para conseguirem participar do mercado matrimonial.

Nesse quadro, um indício das desigualdades entre esses imigrantes dizia respeito ao fato de que a faculdade de tornar-se um comerciante autônomo não era conquistada por todos os membros dessa comunidade. Havia, portanto, açorianos e reinóis que detinham uma posição menos consistente no âmbito do grupo de comerciantes da vila de Paranaguá.

\section{Inauguração de armazém e casamento: etapas do enraizamento social de jovens imigrantes na vila de Paranaguá}

A partir desta seção do artigo são estudados os percursos de dois comerciantes varejistas de origem portuguesa estabelecidos em Paranaguá nos anos 1780. Esses comerciantes eram Antônio José Carvalho e Faustino José Borges. Ao passo que Carvalho contraiu matrimônio em 1780, Borges realizou as suas núpcias em 1781. A comparação entre os processos de enraizamento o social desses indivíduos permite evidenciar de que eram distintas as formas e circunstâncias a partir das quais ocorria o ingresso do imigrante na mencionada vila do litoral da Capitania de São Paulo.

Desse modo, a análise do caso de Faustino Borges comporta indícios de que o jovem imigrante, ao se estabelecer em Paranaguá, não realizava esse intento solitariamente. Antes, esse estabelecimento era realizado, por exemplo, em companhia de seus genitores.

\section{Antônio José Carvalho e as características das conexões sociais de um jovem imigrante}

No dia 29 de dezembro de 1780, o vigário de Paranaguá, Pedro Domingues Paes Leme, iniciou o processo de dispensa matrimonial de Antônio José Carvalho. Oriundo da Freguesia de São Pedro de Aboim, situada no Arcebispado de Braga, em Portugal, ele estava na idade de 24 anos.

Esse processo de dispensa matrimonial fora instaurado para atestar que Carvalho reunia as condições necessárias para contrair matrimônio. Dentre essas condições estavam ser solteiro, não ter prometido núpcias a outra mulher e não ter feito voto de castidade. Nessa oportunidade, foram convocadas três testemunhas para confirmar a veracidade das informações fornecidas por Carvalho. Esse imigrante pretendia contrair matrimônio com Maria de Assunção, natural da vila de Curitiba.

De modo semelhante aos casos de imigrantes que se estabeleceram em Paranaguá na segunda metade do século XVIII, a migração para Paranaguá não 
fora o plano inicial de Carvalho. Ao mesmo tempo, a fixação desse indivíduo em outros municípios do Brasil setecentista não teve sucesso. Trata-se, pois, de situação análoga a de outro imigrante cujo percurso social é analisado neste artigo - Faustino José Borges.

Segundo os relatos contidos no aludido processo de dispensa matrimonial, Carvalho migrara para a cidade portuguesa do Porto aos quinze anos de idade. Permaneceu nesse município durante oito anos. Em seguida, ele se transferiu para a cidade do Rio de Janeiro. Porém, ali residiu por apenas dois meses. Por fim, fixou-se na vila de Paranaguá. ${ }^{14}$

Nota-se, assim, que o estabelecimento desse indivíduo em Paranaguá ocorreu por volta do ano de 1779. Portanto, constata-se que foi de cerca de um ano o tempo decorrido entre a inserção de Carvalho nessa vila e a realização de seu casamento. Trata-se, pois, de evidência de que a absorção do jovem imigrante ao mercado matrimonial da aludida região poderia se desenvolver de maneira célere.

A despeito de sua brevidade, a fixação de Carvalho no Rio de Janeiro não era decorrente de uma escolha fortuita. Antes, ele possuía uma conexão familiar na Capitania do Rio de Janeiro. Um tio de Carvalho era ligado à Igreja Católica. Mais precisamente, esse parente de Carvalho atuava como vigário no município fluminense de Macaé. Tal informação consiste em um indício de que, na segunda metade do século XVIII, a migração de portugueses para o Brasil não era destituída de um planejamento. Um dos aspectos desse planejamento era a manutenção de contatos prévios com compatrícios radicados na colônia.

A historiografia tem salientado que esses contatos eram operacionais para o imigrante receber, ao chegar ao Brasil, uma acolhida e um treinamento na vida mercantil. Tal discussão historiográfica apresenta-se mais amadurecida para o contexto da primeira metade do século XIX. ${ }^{15}$ Desse modo, verifica-se que a tentativa de inserção junto a uma região habitada por compatriotas ou mesmo por parentes não era incomum nas práticas sociais de imigrantes recém-chegados ao litoral sul paulista na segunda metade do século XVIII.

De acordo com Antônio da Silva Neves, testemunha do referido processo de dispensa matrimonial, Carvalho migrara para o Rio de Janeiro para seguir carreira eclesiástica. Porém, tal ingresso não prosperou, visto que, segundo

\footnotetext{
${ }^{14}$ ARQUIVO METROPOLITANO DOM LEOPOLDO E SILVA, MITRA DIOCESANA DE SÃO PAULO. Séries Dispensas e Processos Matrimoniais. Processo de Antônio José Carvalho, 1780.
}

${ }^{15}$ CAVAZZANI, André Luiz Moscaleski. Tendo o sol por testemunha... Op. cit., p. 254. 
Neves, Antônio Carvalho "não era perito nos estudos". ${ }^{16}$ Essa informação consiste, assim, em evidência de que a conexão prévia com um tio clérigo permitiu a Carvalho uma imediata absorção a uma instituição religiosa.

Porém, Carvalho inclinava-se para o desenvolvimento de atividades mercantis. A realização dessas atividades lhe permitiu, por exemplo, estabelecer laços sociais e econômicos com compatriotas no litoral sul paulista. Ou seja, o caso de Antônio Carvalho comporta evidências de que, na sociedade de Paranaguá da segunda metade do século XVIIII, a aproximação entre jovens imigrantes poderia se desdobrar na formação de uma sociedade comercial.

Por fim, as informações encerradas no processo de dispensa matrimonial de Antônio Carvalho são operacionais para constatar aspectos da mobilidade espacial de imigrantes radicados no extremo sul da Capitania de São Paulo, na segunda metade do século XVIII. A noiva de Carvalho era originária de uma vila planáltica e residia em uma freguesia que distava cerca de cinquenta quilômetros do núcleo urbano do município de Paranaguá.

Antônio Carvalho, portanto, não se limitou a constituir vínculos na pequena área urbana na qual estava enraizado. Antes, ele manteve contatos junto a uma freguesia dotada de um pequeno porto. Essa freguesia foi posteriormente elevada pelo Governo Português à condição de município. Essa elevação ocorreu em 1797 e o município recebeu o nome de Vila de Nossa Senhora do Pilar de Antonina. ${ }^{17}$

Em síntese, o malogro da tentativa de fixar-se na capital da colônia impeliu Carvalho a manter contatos sociais que viabilizaram o matrimônio com a integrante de uma freguesia do município de Paranaguá. Essa vila, portanto, era o destino comum de jovens não tiveram êxito em se afirmar como comerciantes ou caixeiros no Rio de Janeiro, nas décadas finais do século XVIII. $* * *$

Dentre as três testemunhas do processo de dispensa matrimonial de Carvalho, duas eram imigrantes portugueses. Antônio da Silva Neves provinha do Arcebispado de Évora, ao passo que Bernardo Dias era oriundo do Arcebispado de Braga. Hilário Araújo, por seu turno, era brasileiro, originário da Capitania da Bahia. Antônio Neves era solteiro, transferira-se para

\footnotetext{
${ }^{16}$ ARQUIVO METROPOLITANO DOM LEOPOLDO E SILVA, MITRA DIOCESANA DE SÃO PAULO. Séries Dispensas e Processos Matrimoniais. Processo de Antônio José Carvalho, 1780.

${ }^{17}$ Acerca da organização do espaço urbano da vila de Antonina e dos aspectos da composição de sua elite social, ver KATO, Allan Thomas Tadashi. Retrato Urbano: estudo da organização socioespacial de Paranaguá, Antonina e Curitiba no início do século XIX. Dissertação (Mestrado em História). Curitiba: Universidade Federal do Paraná, 2011.
} 
Paranaguá em companhia de Antônio Carvalho e junto a este inaugurara um armazém de secos e molhados. Bernardo Dias (22 anos, solteiro) e Hilário de Araújo (58 anos, casado) atuavam como empregados em embarcações.

Dentre os principais interlocutores de Antônio Carvalho em Paranaguá estavam indivíduos que exerciam posições mais subalternas na vida econômica e social da vila de Paranaguá. Eles eram portugueses que não auferiram a condição de comerciantes autônomos. Antes, estavam economicamente sujeitados aos negociantes envolvidos no comércio marítimo.

Em 1783, prestes a atingir a condição de sexagenário, o baiano Hilário de Araújo permanecia situado na categoria dos indivíduos que viviam de andar embarcados, conforme a acepção coeva. De sua parte, Antônio Carvalho e Antônio Neves aproximavam-se pelo fato de que lograram ingressar, na condição de proprietários de armazém, na vida comercial da vila de Paranaguá.

Dessa forma, a análise do perfil social dos indivíduos que testemunharam no processo de Antônio Carvalho permite asseverar que esse indivíduo conseguiu, nos primórdios de sua inserção em Paranaguá, estabelecer vínculos sociais mais sólidos com indivíduos que detinham modesta condição na vida econômica de Paranaguá. Esse caráter modesto era decorrente do fato de serem iniciantes nas lides do comércio varejista, bem como era derivado do fato de permanecerem como empregados da elite dedicada ao comércio marítimo.

\section{Faustino José Borges e a imigração como um projeto familiar}

Em 28 de janeiro de 1781, o vigário Pedro Domingues Paes Leme interpelou a Faustino Borges, então da idade de 23 anos, e a três indivíduos que mantinham relações sociais com esse imigrante natural da Freguesia de Santos Novos, pertencente à jurisdição do município de Lisboa. Borges pretendia casar-se com Ana Maria da Conceição, que, assim como os seus pais, era natural da vila de Paranaguá.

As informações apresentadas por Borges e pelas testemunhas consistem em indícios de que havia famílias portuguesas, na Paranaguá setecentista, que possuíam a inclinação para realizarem migrações internas após o seu estabelecimento no Brasil. Essas informações permitem o conhecimento sobre o modo de envolvimento de Borges na vida econômica de Paranaguá.

Assim, as informações disponíveis no processo de dispensa matrimonial de Borges possibilitam afirmar que a atuação no comércio varejista permanecia como um elemento constante dos homens pertencentes a diferentes gerações de uma parentela de origem portuguesa. Assim, Borges e as suas 
testemunhas voltaram-se a informar sobre a natureza das atividades econômicas e as migrações realizadas pela família do noivo.

Faustino Borges salientou que se estabelecera no Brasil aos dois anos de idade. Ele viera acompanhado de seus pais. O seu genitor era comerciante. Assim, a migração da família Borges para o Brasil ocorrera por volta de 1760.0 enraizamento dessa parentela no Brasil permite acentuar que havia ocasiões nas quais a vila de Paranaguá não era o destino preferido pelos imigrantes. Antes, a transferência para essa vila ocorria após uma tentativa de fixação em outra praça mercantil, notadamente a cidade do Rio de Janeiro. Desse modo, a primeira cidade na qual os Borges se fixaram no Brasil foi o Rio de Janeiro. Permaneceram nesse município durante um ano. Nessa época, o patriarca da família já se dedicava ao comércio.

Em seguida, transferiram-se para Paranaguá. Nesse contexto, Faustino Borges principiou a auxiliar o seu pai nas atividades no comércio varejista. Transcorridos quatro anos, os Borges migraram para a cidade paulista de Santos. Os Borges residiram nesse município durante quatro anos e, por fim, retornaram à vila de Paranaguá. No limiar dos anos 1780, portanto, Faustino Borges já adquirira, do próprio pai, o treinamento necessário para se afirmar como um comerciante autônomo naquela vila. ${ }^{18}$

Tal informação permite um avanço na análise sobre as formas de treinamento de jovens imigrantes na vida mercantil. Há tempos, a historiografia salientou que esse treinamento era realizado pelos compatrícios do imigrante português. A aproximação a um compatrício possibilitava, por exemplo, a oportunidade de envolvimento no mercado matrimonial composto pelas filhas dos comerciantes de uma vila colonial. ${ }^{19}$

De sua parte, o caso de Faustino Borges é uma evidência de que a imigração, em determinadas circunstâncias, assumia um caráter de projeto familiar. Uma vez estabelecidos no Brasil, os membros da parentela permaneciam unidos nas distintas mudanças de município determinadas pelo patriarca. Nesse contexto, herdar a ocupação econômica paterna não era incomum. $* * *$

Dentre as três testemunhas do processo de dispensa matrimonial de Faustino Borges, duas eram naturais de Portugal. Mais precisamente, esses portugueses que testemunharam no processo de Borges eram pertencentes

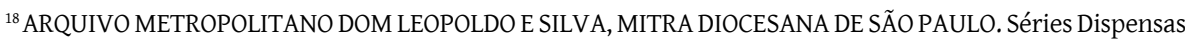
e Processos Matrimoniais. Processo de Faustino José Borges, 1781.

${ }^{19}$ BOXER, Charles. A Idade do Ouro do Brasil: dores do crescimento de uma sociedade colonial. São Paulo: Companhia Editora Nacional, 1969.
} 
a uma geração anterior de imigrantes radicados em Paranaguá. Uma das testemunhas era Custódio Rodrigues, natural da Freguesia de Santa Maria de Lamaçais, no Arcebispado de Braga, em Portugal. Essa testemunha afirmou que estava na idade de 58 anos e atuava tanto como comerciante varejista quanto como embarcado. Afirmou, ainda, que se recordava da época em que os Borges realizaram a sua primeira mudança para a vila de Paranaguá. ${ }^{20}$

Em resumo, Faustino Borges tinha entre os seus principais interlocutores nesse município um antigo imigrante que se consolidara como um pequeno comerciante varejista. Assim, Custódio Rodrigues não se movera para a condição de membro da elite mercantil da localidade. A ausência desse movimento é verificada no fato de que Rodrigues era empregado em embarcações. Ou seja, tratava-se de um indivíduo exerceu simultaneamente mais de uma ocupação econômica.

A segunda testemunha do processo de Faustino Borges chamava-se Domingos Vaz Silva. Natural da Freguesia de Nossa Senhora dos Altos Céus, situada no bispado português de Castelo Branco, Domingos Silva estava com 85 anos de idade quando houve a abertura do citado processo de dispensa matrimonial. Ele mencionou que vivia de suas agências. Ou seja, essa expressão evidencia que ele era um prestador de serviços. Silva não discriminou a natureza dos serviços que prestava. Porém, o emprego dessa categoria, em documentos tais como as listas nominativas, permite identificar indivíduos pouco afortunados. ${ }^{21}$ A terceira testemunha do processo era Manuel Fernandes, natural de Paranaguá, de 72 anos. Ele afirmou que vivia de suas agências.

Dessa forma, ao tempo da realização de seu matrimônio, Faustino Borges era um comerciante varejista que tinha em seu círculo social indivíduos marcados pela modesta condição social. Dentre esses indivíduos, havia portugueses que atingiram idade proveta em condição econômica subalterna, no contexto da vila de Paranaguá. Assim, havia imigrantes de uma geração anterior, nascida no inicio do século XVIII, que permanecia em posição hierarquicamente inferior na sociedade de Paranaguá. Essa subalternidade era determinada pelo fato de terem conquistado um pertencimento à vida econômica local ao exercerem a condição de prestadores de serviços em embarcações ou no meio urbano.

\footnotetext{
${ }^{20}$ ARQUIVO METROPOLITANO DOM LEOPOLDO E SILVA, MITRA DIOCESANA DE SÃO PAULO. Séries Dispensas e Processos Matrimoniais. Processo de Faustino José Borges, 1781.

${ }^{21}$ A esse respeito, ver BACELLAR, Carlos de Almeida Prado. Viver e sobreviver em uma vila colonial: Sorocaba, séculos XVIII e XIX. São Paulo: Annablume/Fapesp, 2001.
} 
O caso de Faustino Borges evidencia, por um lado, que a migração para o Brasil e, em particular, para o litoral sul da Capitania de São Paulo assumia, por vezes, o caráter de projeto familiar. Por outro lado, esse caso permite salientar que Borges e seus interlocutores de origem portuguesa não experimentaram significativa mobilidade social. Borges fora um continuador das atividades comerciais do patriarca. Os seus interlocutores portugueses atingiram a maturidade sem libertarem-se da condição prestadores de serviços mercantis. Eles não ascenderam, por exemplo, à elite de negociantes e proprietários da localidade.

\section{Imigrantes não proprietários e mobilidade espacial: natureza das atividades econômicas de José Francisco dos Remédios e Tomé José Monteiro Braga}

Na vila de Paranaguá, no limiar dos anos 1780, existiam jovens imigrantes (açorianos e reinóis) que não alcançaram a condição de proprietários de armazéns de secos e molhados. Antes, atuavam como empregados em embarcações ou como negociantes que realizavam tratativas comerciais em distintos municípios. Ou seja, eles intermediavam a aquisição, no mercado de Paranaguá, de produtos de fazenda seca. Esses indivíduos, portanto, não pertenciam à categoria dos imigrantes que se sedentarizaram por meio da inserção no núcleo de comerciantes varejistas da referida vila.

Todavia, o fato de permanecerem menos tempo envolvidos na vida social de Paranaguá não criou obstáculos para eles participarem do mercado matrimonial que funcionava nessa localidade. José Francisco e Tomé Braga enquadram-se nessa categoria de imigrantes que lograram contrair núpcias com mulheres oriundas de Paranaguá, ao mesmo tempo em que exerciam ocupações que exigiam prolongadas ausências do município.

\section{José Francisco dos Remédios: a natureza da atividade econômica e o perfil dos interlocutores de um marítimo açoriano}

No dia 28 de setembro de 1783, o vigário interino de Paranaguá, Joaquim da Costa Resende, iniciou o processo de dispensa matrimonial de José Francisco dos Remédios, o qual pretendia casar-se com Maria Francisca de Morais, natural de Paranaguá. Nesse processo é mencionado que o nubente, que estava na idade de 28 anos, era natural da Ilha de São Miguel, pertencente ao Arquipélago dos Açores.

As informações encontradas nesse processo permitem salientar que a vila de Paranaguá não fora a primeira opção de destino para membros da 
comunidade étnica de açorianos e reinóis ali residentes. Antes, o Rio de Janeiro era a cidade na qual eles primeiro buscavam se estabelecer. 0 malogro dessa iniciativa determinava a migração para o litoral sul da Capitania de São Paulo, onde se localizava a vila de Paranaguá. Concernente à sua ocupação profissional, José Francisco salientou que era encarregado da carga e descarga de embarcações. Tal ocupação impelia-o a se ausentar de modo constante de Paranaguá, visto que ele realizava tal atividade em distintos portos.

Dessa forma, José Francisco relatou que migrou da Ilha de São Miguel para a cidade do Rio de Janeiro aos 14 anos de idade. Assim, tal migração ocorreu por volta do ano de 1769. Ele permaneceu nesse município durante seis anos. Em seguida, fixou-se em Paranaguá. ${ }^{22}$

$\mathrm{Na}$ capital da colônia brasileira, portanto, José Francisco não auferiu a oportunidade de integrar o mercado matrimonial. Ao mesmo tempo, a sua inserção no mercado de casamentos em funcionamento em Paranaguá não ocorreu de modo célere. Antes, ele obteve a faculdade de casar-se com integrante da sociedade local após oito anos de residência nesse município. Assim, em relação aos comerciantes autônomos portugueses arrolados neste artigo, o empregado de embarcação José Francisco ingressou de forma mais lenta nos esquemas matrimoniais existentes naquela vila.

Nesse quadro, é necessário salientar que a historiografia permanece carente de análises das oportunidades sociais, trajetórias e práticas familiares de indivíduos que exerciam ocupações ligadas ao mar. ${ }^{23}$ Por conseguinte, a atenção ao caso de José Francisco permite salientar que, no contexto da sociedade de Paranaguá, nos anos 1780, um marítimo foi integrado de modo mais lento ao mercado matrimonial em relação a imigrantes que conquistaram na juventude a condição de comerciantes autônomos.

As três testemunhas do processo de dispensa matrimonial de José Francisco eram empregados em embarcações. Dentre essas testemunhas, duas eram imigrantes. Trata-se, pois, de um indício de que, em Paranaguá, os principais interlocutores daquele açoriano compartilhavam de análogas experiências, tais como a vida marítima e a migração para o Brasil. Mais

\footnotetext{
${ }^{22}$ ARQUIVO METROPOLITANO DOM LEOPOLDO E SILVA, MITRA DIOCESANA DE SÃO PAULO. Séries Dispensas e Processos Matrimoniais. Processo de José Francisco dos Remédios, 1783.

${ }^{23}$ Dentre os esparsos estudos respeitantes a esse tema, cabe destacar OLIVEIRA, Vinícius Pereira de. Sobre águas revoltas: cultura política maruja na cidade portuária de Rio Grande/RS (1835-1834). Tese (Doutorado em História). Porto Alegre: Universidade Federal do Rio Grande do Sul, 2013; e SILVA, Luiz Geraldo. A faina, a festa, o rito: uma etnografia das gentes do mar (séculos XVII ao XIX). Campinas, SP: Papirus, 2001.
} 
precisamente, essas informações evidenciam que os imigrantes, naquela vila, formavam uma comunidade cujos membros distinguiam-se pelas relações horizontais. Essa comunidade, contudo, era formada por imigrantes de distintas gerações.

Para atestar essa afirmação, é necessário ressaltar que uma das testemunhas de José Francisco era o calafate José Fernandes, de 52 anos, casado. Ele era natural da cidade portuguesa do Porto. Esse indivíduo, portanto, tinha como ocupação inspecionar navios e embarcações menores. Nesse particular, estava sob a responsabilidade José Fernandes de zelar pelo pleno funcionamento da bomba de fogo das embarcações. ${ }^{24}$

Por fim, Fernandes afirmou que as informações que possuía a respeito de José Francisco eram do conhecimento de outros camaradas de ofício. Tal afirmação de Fernandes é uma evidência dos extensos contatos sociais mantidos por José Francisco no âmbito de sua rotina como marítimo.

Outra testemunha era Manuel de Campos, 54 anos, casado, natural da Catalunha, na Espanha. Essa informação evidencia, assim, que na segunda metade do século XVIII a vila de Paranaguá não foi receptora apenas de imigrantes de sociedades lusófonas. Esse imigrante afirmou apenas que vivia de andar embarcado. Ou seja, ele não detalhou a sua função no interior das embarcações. Por outro lado, Manuel de Campos relatou que, em distintas ocasiões, esteve embarcado com José Francisco. As testemunhas desse processo, portanto, privavam, em distintas circunstâncias, do convívio com aquele açoriano.

A terceira testemunha do processo era um brasileiro, a saber, o marítimo Elias de Barcelos, natural da Capitania do Espírito Santo. Em 1783, ele estava na idade de 25 anos e era solteiro. Esse indivíduo afirmou que havia nove anos que andava embarcado com José Francisco. Há quase uma década, portanto, Barcelos estava integrado na comunidade de marujos existente em Paranaguá.

Porém, ainda não estava envolvido nos esquemas matrimoniais da vila. Em síntese, verifica-se que José Francisco mantinha relações sociais mais sólidas com adventícios que pertenciam ao seu grupo profissional. No interior desse grupo havia indivíduos que, no âmbito da vila de Paranaguá, adentraram

\footnotetext{
${ }^{24}$ BRASIL. Coleção de Leis do Império do Brasil do ano de 1853. Tomo XIV. Parte I. Rio de Janeiro: Tipografia Nacional, 1853, p. 182. O vocábulo calafetar era empregado para designar ações destinadas ao zelo para com o navio. Mais precisamente, calafetar era o ato de o calafate cobrir "qualquer abertura por onde entra ou passa o Navio a água do mar, o que fazem introduzindo estopa na parte por meio das próprias ferramentas, e ao depois dá-se na mesma parte calafetado, com breu cozido, e preparado, ou com sebo por entre tanto". CAMPOS, Maurício da Costa. Vocabulário marujo. Rio de Janeiro: Oficina de Silva Porto, 1823, p. 30.
} 
de forma mais lenta (ou mesmo estavam afastados) das lógicas de alianças matrimoniais ali vigentes.

\section{Tomé José Monteiro Braga e o mercado matrimonial em uma freguesia do município de Paranaguá}

No dia 17 de janeiro de 1784, o vigário de Paranaguá, Pedro Luís Paes Leme, iniciou o processo de dispensa matrimonial de Tomé José Monteiro Braga. Esse indivíduo era natural da cidade portuguesa de Braga, estava na idade de 20 anos e pretendia contrair núpcias com Maria Clara, cujo sobrenome e ascendência familiar não foram mencionados no processo. ${ }^{25}$ Tomé Braga era um pequeno negociante que realizava suas tratativas comerciais em município do litoral e do primeiro planalto do território do atual Estado do Paraná.

O estudo sobre o percurso social desse indivíduo permite a feitura de duas constatações. Primeiro, as informações contidas em seu processo de dispensa matrimonial evidenciam que havia portugueses que, no contexto do fluxo migratório para o Brasil da segunda metade do século XVIII, não escolheram a vila de Paranaguá como destino prioritário. Antes, a transferência para esse município era decorrente de infausta tentativa de enraizamento na cidade do Rio de Janeiro.

Segundo, compete salientar que havia ocasiões nas quais os imigrantes de origem portuguesa não escolhiam apenas a $1^{a}$ Companhia de Ordenanças, núcleo comercial da vila de Paranaguá, como local de residência. Ao contrário, eles buscavam se estabelecer em uma freguesia que pertencia à jurisdição de Paranaguá. Nessa freguesia, eles integravam um circuito de relações sociais composto por imigrantes de origem portuguesa. Assim, tanto no núcleo urbano da vila de Paranaguá quanto em uma povoação, Morretes, que distava cerca de trinta quilômetros desse núcleo, os portugueses e açorianos tendiam a constituir entre si vínculos sociais.

Tomé Braga relatou ao vigário que migrou para o Brasil aos treze anos de idade. A sua migração ocorreu, assim, por volta do ano de 1777. Inicialmente, estabeleceu-se no Rio de Janeiro. Porém, permaneceu nessa cidade por apenas quatro meses. A dificuldade de imigrantes recém-chegados obterem uma ocupação profissional na então capital do Brasil foi uma situação que se manteve,

\footnotetext{
${ }^{25}$ ARQUIVO METROPOLITANO DOM LEOPOLDO E SILVA, MITRA DIOCESANA DE SÃO PAULO. Séries Dispensas e Processos Matrimoniais. Processo de Tomé José Monteiro Braga, 1784.
} 
ao menos, até a primeira metade do século XIX. ${ }^{26} \mathrm{Em}$ seguida, Braga se fixou na vila de Curitiba, situada no primeiro planalto do atual Estado do Paraná. Por fim, ele se estabeleceu na povoação de Morretes, pertencente à Freguesia de Nossa Senhora do Pilar, a qual, naquele contexto, estava sob o controle administrativo da vila de Paranaguá.

Assim, ao se fixar em uma freguesia do extremo sul da Capitania de São Paulo, Braga se consolidou como um negociante que realizava constantes viagens, sobretudo para a freguesia de São José dos Pinhais, então sob a jurisdição da vila de Curitiba. A solidez de seus vínculos sociais e comerciais com setores da Freguesia de São José e da vila de Curitiba é evidenciada pelo fato de que, segundo Braga, ele permanecia cerca de quatro meses do ano nessas localidades planálticas. Portanto, ao tempo de seu matrimônio, ele não atingira a posição de comerciante que se sedentarizara ao inaugurar loja de secos e molhados.

Em última análise, verifica-se que uma forma de consolidação de Tomé Braga em uma freguesia de Paranaguá consistiu em acomodar-se na posição de pequeno negociante que realizava rotineiros tratos comerciais com membros vilas e freguesias planálticas. Tal posição foi suficiente para ele ser aceito nos esquemas matrimoniais em funcionamento no litoral sul paulista. Portanto, no contexto da vila de Paranaguá, nos anos 1780 , a inauguração de um armazém não era a única forma de o imigrante atingir a posição de comerciante autônomo e ser admitido ao círculo de relações econômicas e familiares de integrantes da sociedade local.

As três testemunhas do processo de dispensa matrimonial de Tomé Braga eram de origem portuguesa. Eram indivíduos com os quais Braga convivia desde a época em que chegara ao Rio de Janeiro. As três testemunhas pertenciam à mesma geração, cujos membros nasceram entre o fim dos anos 1750 e o início dos anos 1760 . Ao mesmo tempo, eles se fixaram na sociedade de Paranaguá por meio da realização de análoga atividade econômica - o desempenho da ocupação de comerciante de fazenda seca.

Em resumo, Braga possuía entre os seus principais interlocutores no litoral sul paulista indivíduos que vivenciaram semelhantes experiências sociais, tais como a migração para o Brasil e a conquista da faculdade de tornar-se um comerciante autônomo. Contudo, a diferença entre Tomé Braga e as três

${ }^{26}$ CAVAZZANI, André Luiz Moscaleski. Tendo o sol por testemunha... Op. cit., p. 261. 
testemunhas do seu processo reside no fato de que elas se sedentarizaram ao inaugurarem armazéns.

A primeira testemunha do processo era Manuel Antônio da Costa, natural do Arcebispado de Braga. Na ocasião, ele estava na idade de 21 anos, era solteiro e habitante do núcleo urbano da Vila de Paranaguá. Porém, no decorrer de 1784 ele contraiu matrimônio Maria Clara de Albertim Lanoya, filha de um antigo escrivão da Câmara de Paranaguá, a saber, Manoel Lobo de Albertim Lanoya. ${ }^{27}$

Ao testemunhar no processo de Tomé Braga, Manuel da Costa afirmou que vivia de seu negócio na vila de Paranaguá. Ou seja, já se acomodara na posição de proprietário de um comércio varejista. Tratava-se de um indivíduo cujo primeiro destino no Brasil fora a cidade do Rio de Janeiro. Assim, as relações sociais de Tomé Braga com portugueses não se restringiam ao contingente de imigrantes estabelecidos na Freguesia do Pilar.

Por outro lado, as informações supracitadas respeitantes a Manuel da Costa consistem em indícios de que, no fim do século XVIII, na sociedade de Paranaguá, havia portugueses que conquistaram a faculdade de contrair núpcias com mulheres cujos ascendentes estavam enraizados na vida administrativa e política da localidade.

A segunda testemunha era o açoriano João Pereira de Oliveira, oriundo da Ilha do Pico. Esse indivíduo era negociante de fazenda seca, estava na idade de 23 anos e era casado. Portanto, os imigrantes com os quais Tomé Braga mantinha relações não tiveram dificuldades para se inserir nos esquemas matrimoniais que vigoravam na sociedade de Paranaguá. A semelhança entre os percursos desses imigrantes consiste no fato de que a acomodação na posição de comerciante foi coeva à inserção naqueles esquemas.

A terceira testemunha desse processo era Antônio José de Carvalho, natural do Arcebispado de Braga. Ele afirmou que estava na idade de 28 anos, morava no núcleo urbano da vila de Paranaguá, era casado e vivia de seu negócio, conforme a expressão da época. Ao mesmo tempo, ele ressaltou que conhecera Tomé Braga na cidade de Lisboa. Portanto, a interlocução entre esses imigrantes já se estendia por cerca de sete anos.

Em resumo, Tomé Braga pertencia a um contingente de imigrantes que ultrapassaram juntos as etapas do treinamento da vida comercial e da obtenção da prerrogativa de atuarem como comerciantes autônomos. Eles eram imigrantes que conviveram em distintas cidades do Brasil e de Portugal.

${ }^{27}$ ARQUIVO METROPOLITANO DOM LEOPOLDO E SILVA, MITRA DIOCESANA DE SÃO PAULO. Séries Dispensas e Processos Matrimoniais. Processo de Manuel Antônio da Costa, 1784. 
Nota-se, assim, uma peculiaridade dos imigrantes que contraíram matrimônio em Paranaguá nos anos 1780. Tal peculiaridade a inclinação para conservar as conexões sociais mantidas desde a época da menoridade com compatrícios envolvidos no aprendizado das atividades comerciais.

\section{Imigração e exercício de ofícios artesanais: os casos de José Soares e Luís Antônio Rodrigues}

O estudo sobre os processos de inserção dos José Soares e Luís Antônio Rodrigues em Paranaguá permite salientar que o exercício de ocupações artesanais era uma forma de imigrantes açorianos e reinóis se estabeleceram na vida comercial dessa vila. A consecução desse estudo também permite corroborar o argumento de que, no contexto da segunda metade do século XVIII, a vila de Paranaguá não fora o destino preferido por jovens imigrantes. Antes, essa vila era procurada por imigrantes após terem obtido treinamento na vida comercial em outros municípios brasileiros.

O desenvolvimento desta análise possibilita a feitura de outra constatação. Essa constatação afirma que a migração para a Capitania de São Paulo, em determinados casos, era um projeto familiar. Ou seja, não eram apenas compatrícios ou brasileiros que proporcionavam um treinamento aos imigrantes recém-chegados em determinados ramos do comércio e do artesanato. Antes, tal treinamento era oferecido por familiares que migraram para aquela capitania. Existiam, pois, diferenças quanto às formas de absorção de jovens imigrantes na sociedade do litoral sul paulista. Conforme destacado nesta seção do artigo, uma das formas de absorção era ser acolhido pelo próprio pai, que imigrara solitariamente para a Capitania de São Paulo.

\section{João Soares e o aprendizado das técnicas de marcenaria: a transmissão de um conhecimento familiar}

No dia 7 de janeiro de 1780 foi aberto em Paranaguá, pelo viário interino Francisco de Meira, o processo de dispensa matrimonial do açoriano José Sores, natural da Ilha de São Miguel. Nessa oportunidade, ele estava com idade de trinta e três anos e atuava como marceneiro. 0 nome da noiva de Soares não foi mencionado no processo. Esse indivíduo se estabelecera no pequeno núcleo urbano da vila de Paranaguá por volta do ano de 1777, aos 31 anos de idade. ${ }^{28}$

\footnotetext{
${ }^{28}$ ARQUIVO METROPOLITANO DOM LEOPOLDO E SILVA, MITRA DIOCESANA DE SÃO PAULO. Séries Dispensas e Processos Matrimoniais. Processo de Manuel Antônio da Costa, 1780.
} 
Nesse sentido, a comunidade de imigrantes portuguesa existente em Paranaguá, nos anos 1780, não era composta apenas por indivíduos que se fixaram no Brasil na menoridade. Portanto, Soares se enquadrava na categoria de um imigrante que não logrou se envolver nos esquemas matrimoniais de sua cidade de origem. Na vila de Paranaguá, em um período de cerca de dois anos, ele aprendera um ofício e fora admito ao mercado matrimonial.

O pai de José Soares, Antônio Soares, ensinou ao seu filho as técnicas da marcenaria. Esse mestre marceneiro argumentou que recomendou a vinda de seu filho para Paranaguá porque ele, José Soares, “estava desarrumado [em sua cidade de origem]". Outro objetivo do patriarca Soares em relação a seu filho era "casá-lo, como, com efeito, assim o pretende". ${ }^{29}$ Esse patriarca informou no processo que residia em Paranaguá há doze anos. Dessa forma, a integração de José Soares em Paranaguá foi viabilizada pelo apoio paterno, que interveio para que o seu descendente não permanecesse desprovido de ocupação e da oportunidade de constituir laços sociais por meio do casamento. A migração de José Soares para o Brasil, em última instância, consiste em um caso de solidariedade familiar.

A contribuição possível do patriarca Soares ao seu filho José consistiu em lhe iniciar nos conhecimentos de um ofício artesanal, de modo a evitar que a ausência de oportunidades econômicas e sociais se prolongasse no percurso daquele açoriano. Nesse quadro, restou a José Soares permanecer sob a dependência do pai, visto que, na ocasião de seu casamento, ainda residia no domicílio paterno.

$$
* * *
$$

A segunda testemunha do processo de José Soares era Manoel José de Faria, que nascera na cidade de Angra do Heroísmo, a qual pertence à Ilha Terceira dos Açores. Nessa ocasião, ele afirmou que estava na idade de 26 anos, era casado e atuava como comerciante. Ele era vizinho da família Soares em Paranaguá. Para além da condição de vizinhos, Manoel José assegurou que mantinha relações de amizade com José Soares. Trata-se, pois, de uma evidência das formas de aproximação entre imigrantes de origem portuguesa em uma vila do litoral sul paulista.

Mais precisamente, essa informação consiste em indício de que imigrantes recém-chegados, no contexto da vila de Paranaguá setecentista, mantinham estreitos vínculos sociais. Esses imigrantes eram distinguidos por análoga condição social. Um aspecto dessa condição era o envolvimento no

${ }^{29} \mathrm{Id}$. 
comércio varejista ou mesmo a conquista da autonomia profissional por meio da atuação em vertente do artesanato. Outro aspecto dessa proximidade era de que esses imigrantes, quando atingiam a maioridade, não tardavam em se imiscuir nos esquemas matrimoniais existentes naquela vila.

A terceira testemunha do processo de dispensa matrimonial era Antônio de Oliveira Pedroso, natural de Paranaguá, casado, comerciante e estava na idade de 44 anos. Oliveira assegurou que conheceu José Soares no Rio de Janeiro e viajaram juntos para Paranaguá. Assim, em 1780, três anos após tal viagem, eles permaneciam como interlocutores.

Em síntese, pode-se destacar que o circuito das relações sociais do açoriano José Soares era composto por indivíduos que atuavam no comércio e no artesanato. Porém, as mais decisivas oportunidades auferidas por esse imigrante foram concedidas pelo próprio pai, não pelos compatrícios ou negociantes locais. Trata-se, pois, de uma diferença fulcral em relação aos processos de absorção social que caracterizavam as trajetórias de portugueses em Paranaguá, no fim do século XVIII. ${ }^{30}$

\section{Circulação por vilas litorâneas e aprendizado da carpintaria: o caso de Luís Antônio Rodrigues}

No dia 19 de maio de 1789, o vigário de Paranaguá, Pedro Domingues Paes Leme, iniciou o processo de dispensa matrimonial do português Luís Antônio de Carvalho. Ele era natural da Freguesia de Nossa Senhora do Castelo, situada no Arcebispado de Braga. Rodrigues era noivo de Inácia Esméria da Rocha, natural da Freguesia de Nossa Senhora do Pilar, e estava na idade de 23 anos.

A atenção ao caso de Luís Rodrigues possibilita reconhecer a diversidade de formas pelas quais ocorria o treinamento de migrantes de origem portuguesa em setores da vida comercial do litoral sul da Capitania de São Paulo. Nesta etapa do artigo, foi demonstrado que o treinamento de João Soares na marcenaria foi conferido pelo próprio pai. Luís Rodrigues, por sua vez, recebeu um treinamento em ramo do artesanato quando se fixou em

\footnotetext{
${ }^{30}$ Para o conhecimento de formas de absorção e mobilidade social de imigrantes portugueses estabelecidos no município de Paranaguá no fim do século XVIII, ver COSTA, Samuel Guimarães da. O último capitão-mor (1782-1857). Curitiba: Editora da Universidade Federal do Paraná, 1988; GOMES, Sandro Aramis Richter. Descentralização e pragmatismo: condições sociais de produção das memórias históricas de Antônio Vieira dos Santos (Morretes e Paranaguá, décadas de 1840 e 1850). Dissertação (Mestrado em História). Curitiba: Universidade Federal do Paraná, 2012.
} 
uma vila do litoral sul paulista, a saber, Cananeia. A sua transferência para o Brasil, assim, ocorreu por volta do ano de $1779 .{ }^{31}$

Aos treze anos, Rodrigues migrou da Freguesia do Castelo para a cidade de Lisboa. Permaneceu durante um ano na capital portuguesa. Quando se estabeleceu no Brasil, residiu na vila paulista de Santos e, em seguida, estabeleceu-se em na vila de Cananeia. Foi nesse município que Rodrigues aprendeu o ofício de carpinteiro. Por fim, em 1785, quando estava na idade de 19 anos, ele se fixou na vila de Paranaguá.

O percurso de Rodrigues consiste, pois, em uma evidência de uma dinâmica de treinamento e mobilidade de jovens de origem portuguesa em funções comerciais e artesanais em sociedades do litoral sul paulista. Tal dinâmica permaneceu em funcionamento, ao menos, até as primeiras décadas do século XIX. ${ }^{32}$

As três testemunhas do processo de dispensa matrimonial de Luís Rodrigues eram carpinteiros. Dentre essas testemunhas, uma era natural do Reino de Portugal. Portanto, a inserção em um ramo dos ofícios artesanais, na vila de Paranaguá setecentista, não era um destino incomum de jovens portugueses.

A testemunha que provinha de Portugal era João José Vieira, natural da Vila do Conde, no Bispado no Porto. Esse carpinteiro estava na idade de 25 anos e conhecera Luís Rodrigues há cerca de uma década, na vila de Cananeia. Portanto, João Vieira também se enquadrava na categoria de um imigrante cujo percurso foi marcado, em seu início, pela circulação por vilas do litoral sul da Capitania de São Paulo. Dessa forma, João Vieira e Luís Rodrigues eram indivíduos que se aproximavam pelo fato de pertencerem à mesma geração (nasceram na década de 1760) e lograrem adentrar aos esquemas matrimoniais na vila de Paranaguá.

As outras duas testemunhas eram naturais de vilas do litoral sul de São Paulo. 0 carpinteiro José Monteiro Gomes, então na idade de 26 anos, era

\footnotetext{
${ }^{31}$ ARQUIVO METROPOLITANO DOM LEOPOLDO E SILVA, MITRA DIOCESANA DE SÃO PAULO. Séries Dispensas e Processos Matrimoniais. Processo de Luís Antônio Rodrigues.

${ }^{32} \mathrm{Em}$ 1826, por exemplo, o imigrante português Antônio Vieira dos Santos (1784-1854), residente na Freguesia de Morretes, estava envolvido em uma lógica de recrutamento de caixeiros que envolvia indivíduos da vila de Cananeia. Nessa oportunidade, Vieira dos Santos estava empenhado em articular, por um lado, a inserção de um sobrinho no ofício de caixeiro e, por outro lado, busca atrair para Morretes em caixeiro de Cananeia. Leia-se o seguinte extrato das memórias de Vieira dos Santos: Em 23 Sesta fra mandei buscar em Paran ${ }^{\mathrm{a}}$ o meu sobr ${ }^{\circ}$ Antonio $\mathrm{p}^{\mathrm{a}} \mathrm{Caix}^{\mathrm{ro}}$ do $\mathrm{Cap}^{\mathrm{m}}$ Franco J de Freitas tendo falado a elle sobre este fim: o qual chegou no dia 29 de manhã de t. Falei com o Freitas pa elle hir; mas tornei em 2 de Julho a falar pa elle não hir sem vir pro outro de Cananeia". CAVAZZANI, André Luiz Moscaleski e GOMES, Sandro Aramis Richter. Antônio Vieira dos Santos... Op. cit., p. 58.
} 
natural e residente em Paranaguá e, à época, permanecia solteiro. A terceira testemunha era Guilherme Aguiar Arantes, 26 anos, solteiro. Ele era natural e residente na vila de Cananeia. Constata-se, assim, que ambas as testemunhas não lograram, até o fim da década de 1780, ingressar no mercado matrimonial das suas vilas de origem.

De outra parte, os casos de Luís Rodrigues e José Vieira apresentam-se como indícios que a obtenção de uma qualificação profissional, pelo imigrante recém-chegado, era comumente acompanhada pela oportunidade de constituir vínculos familiares. A atuação como um comerciante ou artesão autônomo e o estabelecimento de conexões familiares consistiam nos limites das oportunidades angariadas por açorianos e reinóis, no município de Paranaguá, no decorrer dos anos 1780. A obtenção dessas oportunidades, para os indivíduos na faixa etária dos 20 anos, significava o encerramento do domínio sobre eles exercido por indivíduos que os treinaram nas lides do comércio e do artesanato.

\section{Considerações finais}

A finalidade deste artigo consistiu em produzir um conhecimento sobre a natureza das oportunidades sociais e econômicas de jovens açorianos e portugueses que contraíram matrimônio na vila de Paranaguá, na Capitania de São Paulo, ao longo dos anos 1780. Inicialmente, demonstrou-se neste artigo que o exercício do comércio era um destino comum aos jovens imigrantes na vila de Paranaguá. A inauguração de um armazém de secos e molhados e a realização de um casamento com integrante da sociedade local eram os principais elementos do processo de inserção de portugueses naquela localidade. Esses indivíduos acomodavam-se, frequentemente, na condição de pequenos comerciantes varejistas.

A despeito de seu caráter modesto no contexto das ocupações mercantis, a abertura de loja de secos e molhados era um episódio que implicava o fim a dependência dos imigrantes em relação aos negociantes que os treinaram nas lides do comércio. Ao mesmo tempo, foi demonstrado neste estudo que o estabelecimento de portugueses em Paranaguá foi, em determinados casos, decorrente de um projeto familiar. Ou seja, houve indivíduos pertencentes a uma mesma parentela que migraram juntos para aquela vila litorânea. Esses familiares permaneceram unidos no exercício de atividades na vida mercantil do município.

Por conseguinte, ressaltou-se no presente artigo que havia imigrantes cujo percurso social, nos anos 1780, era marcado por expressiva mobilidade 
espacial. Esses indivíduos não se sedentarizaram como proprietários de armazéns ou artesãos. Antes, permaneciam em constante circulação por vilas adjacentes ao município de Paranaguá com a finalidade de realizar a comercialização de determinados bens de consumo.

$\mathrm{Na}$ época em que estavam na faixa etária dos 20 anos de idade, esses imigrantes não alcançaram a condição de proprietários, seja de uma loja, seja de uma embarcação. Ao contrário, havia imigrantes que eram empregados de proprietários dessas embarcações. Desse modo, eles se dedicavam ao carregamento e descarregamento de mercadorias em distintos portos brasileiros. Essa ausência de uma vida sedentária, contudo, não gerou obstáculos para eles estabelecerem sólidos vínculos sociais na vila de Paranaguá e obterem a faculdade de ali contrair matrimônio.

O exercício dessa ocupação também era peculiar a imigrantes radicados em Paranaguá na primeira metade do século XVIII. Assim, as informações analisadas nesse estágio do artigo permitiram reconhecer a conservação de imigrantes em idade provecta em uma posição mais subalterna na vida econômica daquela vila.

Por fim, constatou-se que o exercício de ocupações artesanais, tais como a carpintaria e a marcenaria, foram características às trajetórias de jovens açorianos e portugueses residentes em Paranaguá nos anos 1780. A semelhança entre os imigrantes açorianos e portugueses nesse município consistiu no fato de que eles não tardaram a ser incorporados ao mercado matrimonial da região. Em algumas ocasiões, essa incorporação foi mais célere do que a incorporação de membros da sociedade local.

De outra parte, na vila de Paranaguá, no mencionado decênio, havia a inclinação de os imigrantes atuantes em uma idêntica área do comércio ou do artesanato conservarem entre si vínculos sociais. Esses vínculos eram, por vezes, criados em Portugal ou em uma vila do litoral brasileiro na época em que esses indivíduos estavam na menoridade e principiavam o aprendizado de ofícios inerentes à vida mercantil.

Os estudos de caso empreendidos ao longo deste artigo comportam evidências de que os imigrantes de origem portuguesa estabelecidos em Paranaguá, na década de 1780 , formavam uma comunidade. Os membros dessa comunidade eram próximos em virtude da equivalente condição profissional e da vivência de semelhantes experiências, tais como a forma de treinamento em determinado ramo da vida econômica.

Artigo recebido para publicação em 25/01/2017

Artigo aprovado para publicação em 02/06/2017 